\title{
SISTEM INFORMASI PEMBELAJARAN ENGLISH GRAMMAR BERBASIS WEB
}

\author{
Tati Mardewi ${ }^{1}$, Thalia Devega Tires ${ }^{2}$ \\ ${ }^{1,2}$ Program Studi Manajemen Informatika, AMIK BSI Bogor \\ ${ }^{1)} \underline{\text { tati.tdi@bsi.ac.id }},{ }^{2)}$ devega66@gmail.com
}

\begin{abstract}
Abstrak - Sistem Informasi Pembelajaran English Grammar Berbasis Web memiliki manfaatnya yang sangat penting dalam usaha untuk meningkatkan kemampuan berbahasa Inggris. Sebagaimana diketahui bahasa Inggris merupakan bahasa internasional yang digunakan hampir disemua aspek kehidupan dan merupakan kebutuhan yang sekarang ini tidak bisa dihindari. Salah satu aspek dalam belajar bahasa Inggris adalah dengan mempelajari grammar. Grammar menentukan bagaimana kata-kata disusun dalam membentuk unit-unit bahasa yang bermakna. Karena masih kurangnya media online untuk mempelajari grammar, hal ini merupakan kesempatan bagi penulis membuat website e-learning untuk pembelajaran English grammar yang bisa dikerjakan dimanapun dengan memanfaatkan media elektronik yang terhubung dengan koneksi internet. Penulis menggunakan pengembangan system dengan motode perangkat lunak waterfall yang terdiri dari: Analisis kebutuhan perangkat lunak, desain, pembuatan kode program, pengujian, pendukung dan pemeliharaan serta menggunakan teknik observasi dan studi pustaka dalam pengumpulan data yang dibutuhkan. Website e-learning ini dapat menampilkan materi pelajaran serta memberikan latihan soal. Hasil penelitian ini akan lebih memudahkan pengajar, pelajar atau para user dalam mempelajari grammar bahasa Inggris karena e-learning ini sangat mudah dalam penggunaannya dan juga akan mengefektifkan waktu pengguna.
\end{abstract}

Kata Kunci: Website e-learning, Grammar, Waterfall, dan Internet .

Abstract - Information system of learning English grammar based on web has a significant function in improving our English ability. As we know that English is an international language which is used almost in all aspects of life. It is a necessity that is currently inevitable. One of the aspects of learning English is grammar. Grammar determines how words are arranged in the form of meaningful language units. Due to the lack of online media to learn grammar, this is an opportunity for writers to create e-learning website for learning English grammar that can be done everywhere by utilizing electronic media that is connected to internet. The author uses the development of motion waterfall software which consists of the determination, analysis of specifications, design system, information systems, implementation unit testing by using observation techniques and library studies in collecting data required. This e-learning website can display the subject matter as well as provide practice questions. The result of this research will help the teachers and students or users learn English grammar easier because it more effective in usage and time.

Keywords: Website e-learning, Grammar, Waterfall, and Internet.

\section{PENDAHULUAN}

Kemajuan ilmu pengetahuan dan teknologi sistem informasi berkembang pesat, kebutuhan akan informasi yang cepat menjadi babak baru dalam pengembangan berbagai perangkat, baik perangkat lunak maupun perangkat keras yang dapat menunjang untuk pencarian informasi. Perkembangan teknologi internet pun telah menjadi hal yang familiar dalam kehidupan masyarakat, salah satunya membantu dalam proses belajar mengajar. Internet (Interconnected Network) adalah jaringan komputer yang menghubungkan antar jaringan secara global, internet juga dapat disebut jaringan dalam suatu jaringan yang luas [1]. Salah satu kemudahan penggunaan akses internet adalah adanya sistem informasi berbasis web dengan menggunakan jaringan komputer dan ruang penyimpanan data dalam bentuk database. Website adalah sebutan bagi sekelompok halaman web (web page), dan umumnya merupakan bagian dari suatu nama domain (domain name) atau sub domain dalam World 
Wide Web (www) di internet [2]. Hubungan antara halaman web disebut dengan hyperlink. Sedangkan teks yang dijadikan media penghubung disebut dengan hypertext. Basis data adalah sekumpulan informasi yang diatur agar mudah dicari. Dalam arti umum basis data adalah sekumpulan data yang diproses dengan bantuan komputer yang memungkinkan data dapat diakses dengan mudah dan tepat, yang dapat digambarkan sebagai aktivitas dari satu atau lebih organisasi yang berelasi [3].

Saat ini banyak metode belajar mengajar yang di gunakan, salah satunya electronic learning atau lebih sering kita kenal dengan istilah e-learning. E-learning adalah suatu sistem pembelajaran yang digunakan sebagai sarana dan proses belajar mengajar yang dilaksanakan tanpa harus bertatap muka secara langsung antar pengajar dan pelajar [4]. Dengan adanya e-learning membantu para pengajar dan pelajar atau mahasiswa dalam proses belajar karena $e$-learning sifatnya lebih efisiensi waktu, serta dapat berbagi banyak ilmu pengetahuan dan keterampilan kepada masyarakat, e-learning juga dapat dilakukan secara informal dengan interaksi yang lebih sederhana.

Sementara itu bahasa inggris merupakan bahasa internasional yang digunakan hampir disemua aspek kehidupan dan merupakan salah satu kebutuhan yang sekarang ini tidak bisa dihindari. Dengan menguasai bahasa inggris akan mempermudah kita dalam mendapatkan pekerjaan ataupun sekedar berkomunikasi dengan dunia luar. Untuk mengusainya tentu saja kita harus mempunyai dasar dalam mempelajarinya, salah satu yang menjadi kebutuhan dalam belajar bahasa inggris adalah dengan mempelajari grammar. Grammar (tata bahasa) adalah ilmu yang mempelajari tentang cara penyusunan kata-kata yang memiliki wujud tertentu menjadi sebuah kalimat yang tepat [5]. Oleh karena itu, tersedianya media belajar grammar secara online adalah hal yang membantu para penggunanya dalam proses pembelajaran bahasa Inggris. Proses pengembangan perangkat lunak dengan mempergunakan metode waterfall, pengumpulan data melalui studi pustaka dan observasi beberapa website yang berhubungan dengan pembelajaran bahasa Inggris.

Berdasarkan permasalahan yang terjadi diatas, penulis memilih untuk membuat website elearning yang mempelajari grammar dan memberikan judul "SISTEM INFORMASI PEMBELAJARAN ENGLISH GRAMMAR BERBASIS WEB"

\section{METODE PENELITIAN}

Metode yang digunakan penulis dalam penelitian ini adalah :

2.1. Model Waterfall

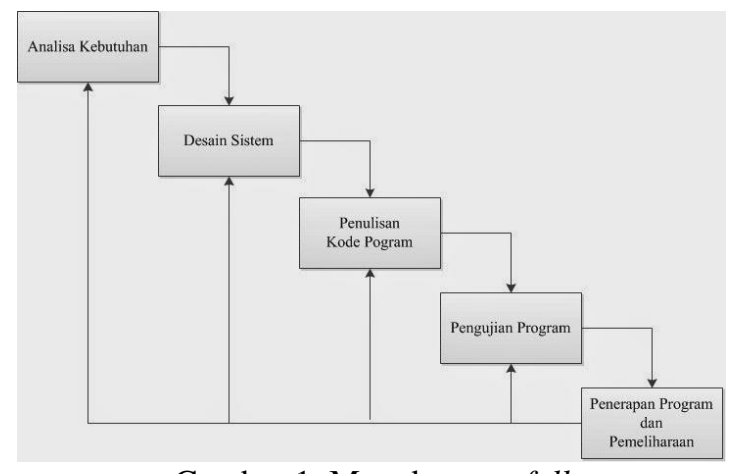

Gambar 1. Metode waterfall

Model air terjun menyediakan pendekatan antara perangkat lunak secara sekuensial atau terurut dimulai dari analisis, desain, pengkodean, pengujian dan tahap pendukung (support).

Tahapan-tahapan model waterfall sebagai berikut :

a. Analisis kebutuhan perangkat lunak

Dalam pembuatan program ini, kurangnya website e-learning yang membahas tentang pembelajaran grammar serta belum banyak tersedianya konten belajar grammar baik dalam bentuk artikel ataupun dalam bentuk media online lainnya. Dan solusi dari permasalahan yang terjadi diatas yaitu dengan membuat website e-learning yang khusus mempelajari cara penggunaan grammar sebagai dasar untuk bisa berbahasa inggris. 
b. Desain

Pada tahapan desain penulis melakukan rancangan pemetaan data yang digambarkan melalui ERD dan LRS untuk pembuatan database dengan isi tabel admin, tabel user dan lain-lain. Serta menggambarkan alur kerja website menggunakan struktur navigasi untuk cara penggunaan website dan proses pembuatan layout rancangan antar muka yang terdiri dari front end yaitu halaman yang bisa di akses oleh pengguna seperti halaman materi belajar dan latihan soal dan back end untuk administrator yang mengatur halaman penambahan materi belajar dan lain sebagainya.

c. Pembuatan kode program

Dalam tahapan ini penulis menerapkan beberapa bahasa pemrograman yaitu HTML untuk membuat tampilan, PHP untuk menghubungkan dengan basis data, serta CSS, dan beberapa bahasa pemrograman lainnya sebagai pendukung pembuatan website.

d. Pengujian

Pengujian dilakukan setelah selesainya pembuatan website apakah website yang telah dibuat sesuai keinginan dan semua proses berjalan sesuai dengan tujuan awal dan untuk mencari kesalahan serta kelemahan dalam website agar dapat diperbaiki. Dalam hal ini halaman login merupakan halaman pertama yang diakses oleh para pengguna dan setelah login pengguna akan masuk dalam halaman materi yang berisi tentang berbagai materi pembelajaran grammar.

e. Pendukung (support) atau pemeliharaan (maintenance)

Penulis melakukan proses pendukung atau pemeliharaan seperti halnya memperbaiki data dengan rutin melakukan scan antivirus dan lain sebagainya, serta peningkatan kinerja dengan mengikuti perkembangan zaman agar web dalam selalu up to date, dan berbagai hal ditujukan agar website selalu dalam kondisi baik.

\subsection{Teknik pengumpulan data}

a. Pengamatan langsung (Observasi)

Penulis melakukan kegiatan pengamatan secara langsung seperti mengunjungi situs-situs website e-learning yang sudah ada terlebih dahulu agar mengetahui apa saja kebutuhan serta fasilitasfasilitas yang diberikan untuk meningkatkan jumlah pengunjung.

b. Study kepustakaan

Penulis melakukan pengumpulan dari beberapa referensi, bahan kuliah, mencari, membaca dan mempelajari buku mengenai bahasa pemrograman serta hal-hal lain yang diperlukan untuk membangun sebuah website e-learning serta mempelajari buku-buku yang membahas tentang bahasa Inggris dan gramnar.

\section{HASIL DAN PEMBAHASAN}

Sistem yang diusulkan berdasarkan identifikasi kebutuhan perancangan system web dengan penggambaran Entity Relationship Diagram yang terkait. Berdasarkan gambar 2 dibawah, entitas yang terbentuk dari hasil rancangan database adalah: entitas user dengan atribut: kata sandi, user name, email, nama lengkap, kode user, berikutnya entitas materi dengan atribut: kode materi, judul materi, isi materi, kode_user, berikutnya entitas admin dengan atribut: kode admin, nama_admin, kata_sandi, selanjutnya entitas nilai dengan atribut: jml_nilai, jml_benar, jml_salah, id_nilai, kode_user, selanjutnya entitas bank_latihan_soal dengan atribut: jawab_d, jawab_c, jawab_b, jawab_a, jawab, kode_materi, no_soal, pertanyaan, kode_soal, berikutnya entitas nilai_detail degan atribut jawaban_soal, kode_soal, id_nilai, nilai_detail_id. Relasi yang terjadi adalah antara entitas user dengan entitas materi, kardinalitas 1:m, sedangkan entitas materi dengan entitas admin, kardinalitas 1:m, selanjutnya, entitas user dengan entitas nilai, kardinalitas 1:m, selanjutnya entitas materi dengan entitas bank_latihan_soal, kardinalitas 1:m, selanjutnya entitas nilai dengan nilai_detail, kardinalitas 1:m, selanjutnya entitas bank_latihan_soal dengan entitas nilai_detail, kardinalitas m:n. 


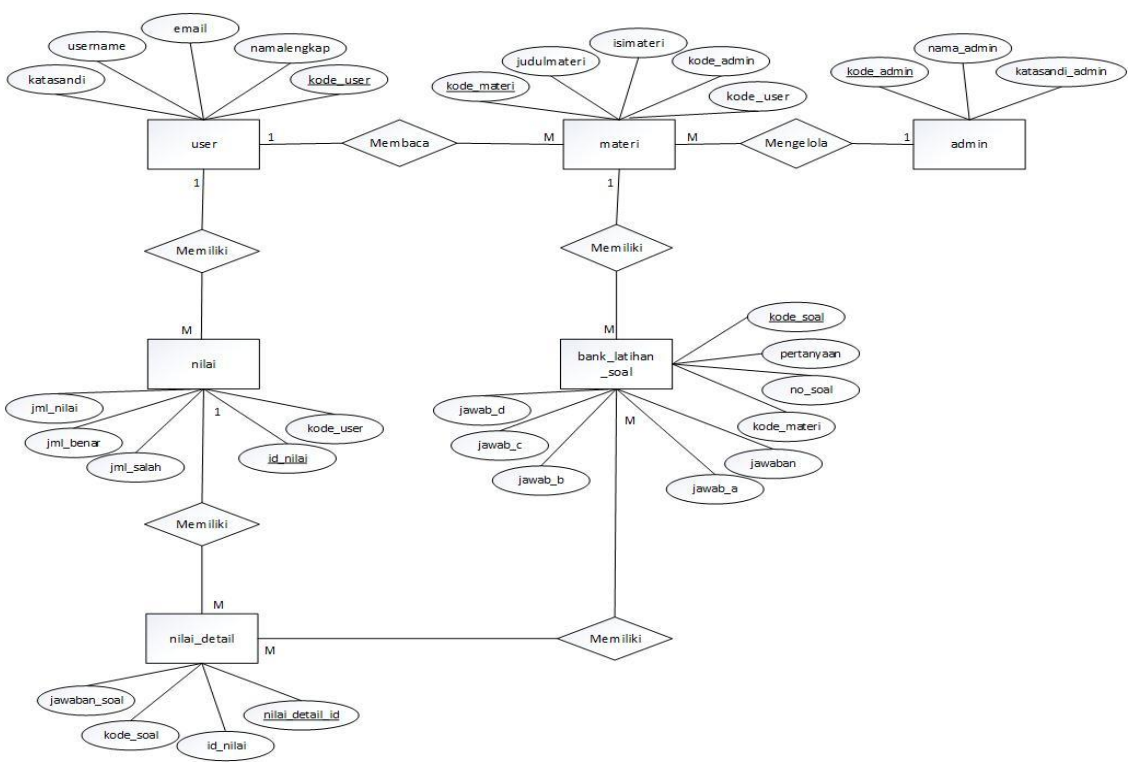

Gambar 2. ERD

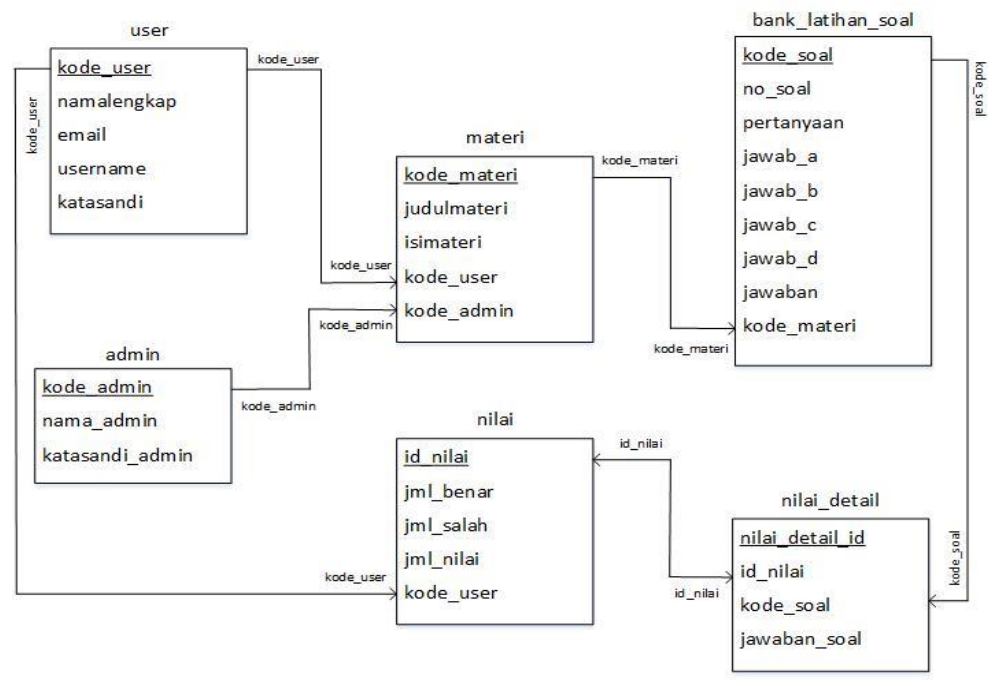

Gambar 3. LRS

Gambar 3 adalah rancangan LRS yang dibuat berdasarkan ERD pada gambar 2.

Sebelum menyusun aplikasi multimedia ke dalam sebuat software, menentukan alur apa yang akan digunakan dalam aplikasi yang dibuat adalah suatu yang harus dipersiapkan”. Berikut ini struktur navigasi yang dirancang oleh penulis : 
1. Struktur Navigasi User.

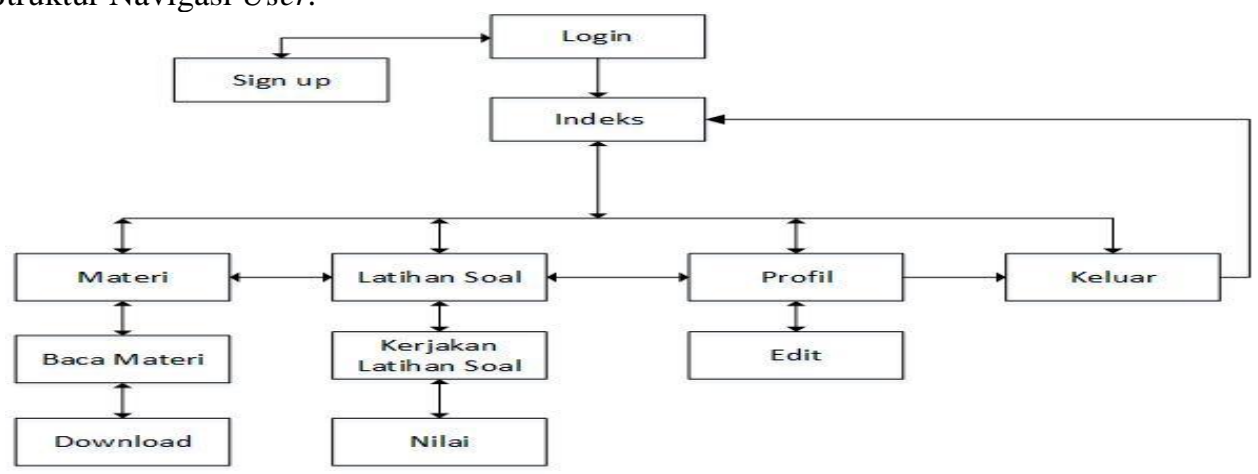

Gambar 4. Struktur Navigasi User

Gambar 4 adalah struktur navigasi halaman pengunjung pada website.

2. Struktur Navigasi Admin.

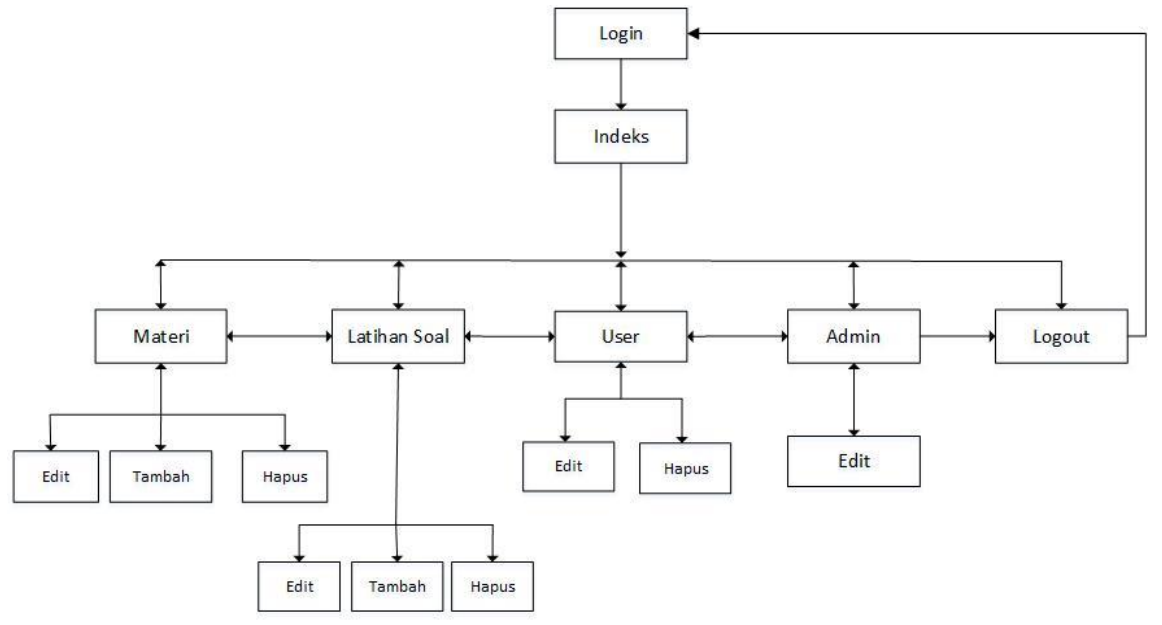

Gambar 5. Struktur Navigasi Admin

Gambar 5 adalah struktur navigasi halaman admin pada website

Pengujian terhadap program yang dibuat dengan menggunakan black box testing yang fokus terhadap masukan dan keluaran program.

1. Pengujian terhadap Form Login User

Tabel 1. Hasil Pengujian Halaman Login User

\begin{tabular}{|c|c|c|c|c|c|}
\hline No. & $\begin{array}{c}\text { Skenario } \\
\text { Pengujian }\end{array}$ & Test Case & $\begin{array}{c}\text { Hasil yang } \\
\text { diharapkan }\end{array}$ & $\begin{array}{c}\text { Hasil } \\
\text { pengujian }\end{array}$ & Kesimpulan \\
\hline 1. & $\begin{array}{l}\text { Username dan } \\
\text { password tidak diisi } \\
\text { kemudian klik login }\end{array}$ & 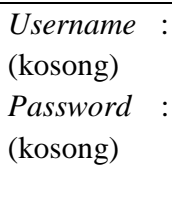 & $\begin{array}{lr}\text { Sistem } & \text { menolak } \\
\text { akses } & \text { login, } \\
\text { "username } & \text { dan } \\
\text { password } & \text { harus } \\
\text { diisi" } & \end{array}$ & Sesuai harapan & Valid \\
\hline 2. & $\begin{array}{l}\text { Mengetikan } \\
\text { username dan } \\
\text { mengosongkan } \\
\text { password kemudian } \\
\text { klik login }\end{array}$ & $\begin{array}{l}\text { Username : } \\
\text { thalia } \\
\text { password : } \\
\text { (kosong) }\end{array}$ & $\begin{array}{lr}\text { Sistem } & \text { menolak } \\
\text { akses } & \text { login, } \\
\text { "password } & \text { harus } \\
\text { diisi" } & \end{array}$ & Sesuai harapan & Valid \\
\hline 3. & $\begin{array}{l}\text { Mengosongkan } \\
\text { username dan }\end{array}$ & $\begin{array}{l}\text { Username : } \\
\text { (kosong) }\end{array}$ & $\begin{array}{l}\text { Sistem menolak } \\
\text { akses login, }\end{array}$ & Sesuai harapan & Valid \\
\hline
\end{tabular}




\begin{tabular}{|c|c|c|c|c|c|}
\hline No. & $\begin{array}{c}\text { Skenario } \\
\text { Pengujian }\end{array}$ & Test Case & $\begin{array}{l}\text { Hasil yang } \\
\text { diharapkan }\end{array}$ & $\begin{array}{c}\text { Hasil } \\
\text { pengujian }\end{array}$ & Kesimpulan \\
\hline & $\begin{array}{l}\text { mengetikan } \\
\text { password kemudian } \\
\text { klik login }\end{array}$ & $\begin{array}{l}\text { password : } \\
12345\end{array}$ & $\begin{array}{l}\text { "username harus } \\
\text { diisi" }\end{array}$ & & \\
\hline 4. & $\begin{array}{l}\text { Mengetikan salah } \\
\text { satu kondisi salah } \\
\text { pada username atau } \\
\text { password kemudian } \\
\text { klik login }\end{array}$ & $\begin{array}{l}\text { Username : } \\
\text { thalia } \\
\text { password : } \\
\text { abcde } \\
\text { (salah) }\end{array}$ & $\begin{array}{lr}\text { Sistem } & \text { menolak } \\
\text { akses } & \text { login, } \\
\text { "username } & \text { dan } \\
\text { password } & \text { tidak } \\
\text { sama" } & \end{array}$ & Sesuai harapan & Valid \\
\hline 5. & $\begin{array}{l}\text { Mengetikan } \\
\text { username dan } \\
\text { password dengan } \\
\text { benar kemudian klik } \\
\text { login }\end{array}$ & $\begin{array}{l}\text { Username : } \\
\text { thalia } \\
\text { password : } \\
12345\end{array}$ & $\begin{array}{l}\text { Sistem menerima } \\
\text { akses login dan } \\
\text { langsung } \\
\text { menampilkan index }\end{array}$ & Sesuai harapan & Valid \\
\hline
\end{tabular}

Table 1 berada pada tahap pengujian form login user, dimana data yang diinput salah ataupun benar yang berada pada kolom "skenario pengujian" akan menghasilkan komentar yang berada pada kolom "hasil yang diharapkan".

\section{Pengujian terhadap Form Daftar User}

Tabel 2. Hasil Pengujian Halaman Daftar User

\begin{tabular}{|c|c|c|c|c|c|}
\hline No. & $\begin{array}{l}\text { Skenario } \\
\text { Pengujian }\end{array}$ & Test Case & Hasil yang diharapkan & $\begin{array}{l}\text { Hasil } \\
\text { pengujian }\end{array}$ & Kesimpulan \\
\hline 1. & $\begin{array}{lr}\text { Full name, } e- \\
\text { mail, } \\
\text { dansername password } \\
\text { tidak disi } \\
\text { kemudian } \\
\text { sign up }\end{array}$ & 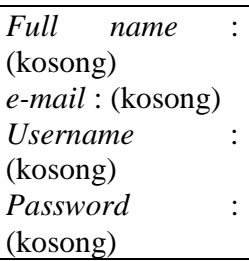 & $\begin{array}{l}\text { Sistem menolak akses } \\
\text { sign up, "full name, e- } \\
\text { mail, user name dan } \\
\text { password tidak boleh } \\
\text { kosong" }\end{array}$ & $\begin{array}{l}\text { Sesuai } \\
\text { harapan }\end{array}$ & Valid \\
\hline 2. & $\begin{array}{lr}\text { Mengisi } & \text { salah } \\
\text { satu kondisi } \\
\text { dan yang lain } \\
\text { tidak } & \text { diisi } \\
\text { kemudian } & \text { klik } \\
\text { sign up } & \end{array}$ & $\begin{array}{l}\text { Full name: Thalia } \\
\text { Devega } \\
\text { e-mail : (kosong) } \\
\text { Username } \\
\text { (kosong) } \\
\text { Password } \\
\text { (kosong) }\end{array}$ & $\begin{array}{l}\text { Sistem menolak akses } \\
\text { sign up, "E-mail, user } \\
\text { name dan password } \\
\text { tidak boleh kosong" }\end{array}$ & $\begin{array}{l}\text { Sesuai } \\
\text { harapan }\end{array}$ & Valid \\
\hline 3. & $\begin{array}{l}\text { Mengisi semua } \\
\text { kondisi, full } \\
\text { name, e-mail, } \\
\text { username dan } \\
\text { password } \\
\text { kemudian klik } \\
\text { sign up }\end{array}$ & $\begin{array}{l}\text { Full name: Thalia } \\
\text { Devega } \\
\text { e-mail } \\
\text { devega66@ } \\
\text { gmail.com } \\
\text { Username: Thalia } \\
\text { Password: } 12345\end{array}$ & $\begin{array}{l}\text { Sistem menerima data } \\
\text { pendaftaran user dan } \\
\text { langsung memiliki akses } \\
\text { untuk login. }\end{array}$ & $\begin{array}{l}\text { Sesuai } \\
\text { harapan }\end{array}$ & Valid \\
\hline
\end{tabular}

Table 2 berada pada tahap pengujian form daftar user, dimana data yang diinput salah ataupun benar yang berada pada kolom "skenario pengujian" akan menghasilkan komentar yang berada pada kolom "hasil yang diharapkan". 
3. Pengujian terhadap Form Login Admin

Tabel 3. Hasil Pengujian Halaman Login Admin

\begin{tabular}{|c|c|c|c|c|c|}
\hline No. & Skenario Pengujian & Test Case & Hasil yang diharapkan & $\begin{array}{c}\text { Hasil } \\
\text { pengujian }\end{array}$ & Kesimpulan \\
\hline 1. & $\begin{array}{l}\text { Username dan } \\
\text { password tidak diisi } \\
\text { kemudian klik login }\end{array}$ & $\begin{array}{l}\text { Username : } \\
\text { (kosong) } \\
\text { Password : (kosong) }\end{array}$ & $\begin{array}{l}\text { Sistem menolak akses } \\
\text { login, "username dan } \\
\text { password harus diisi" }\end{array}$ & Sesuai harapan & Valid \\
\hline 2. & $\begin{array}{l}\text { Mengetikan } \\
\text { username dan } \\
\text { mengosongkan } \\
\text { password kemudian } \\
\text { klik login }\end{array}$ & $\begin{array}{l}\text { Username : admin } \\
\text { password: (kosong) }\end{array}$ & $\begin{array}{lcc}\text { Sistem } & \text { menolak } & \text { akses } \\
\text { login, "password } & \text { harus } \\
\text { diisi" } & & \\
& & \end{array}$ & Sesuai harapan & Valid \\
\hline 3. & $\begin{array}{l}\text { Mengosongkan } \\
\text { username dan } \\
\text { mengetikan password } \\
\text { kemudian klik login }\end{array}$ & $\begin{array}{l}\text { Username : } \\
\text { (kosong) password: } \\
\text { admin }\end{array}$ & $\begin{array}{l}\text { Sistem menolak akses } \\
\text { login, "username harus } \\
\text { diisi" }\end{array}$ & Sesuai harapan & Valid \\
\hline 4. & $\begin{array}{l}\text { Mengetikan salah } \\
\text { satu kondisi salah } \\
\text { pada username atau } \\
\text { password kemudian } \\
\text { klik login }\end{array}$ & $\begin{array}{l}\text { Username : admin } \\
\text { password : } 12345 \\
\text { (salah) }\end{array}$ & $\begin{array}{l}\text { Sistem menolak akses } \\
\text { login, "username dan } \\
\text { password tidak sama" }\end{array}$ & Sesuai harapan & Valid \\
\hline 5. & $\begin{array}{l}\text { Mengetikan } \\
\text { username dan } \\
\text { password dengan } \\
\text { benar kemudian klik } \\
\text { login }\end{array}$ & $\begin{array}{l}\text { Username : admin } \\
\text { password : admin }\end{array}$ & $\begin{array}{l}\text { Sistem menerima akses } \\
\text { login dan langsung } \\
\text { menampilkan index }\end{array}$ & Sesuai harapan & Valid \\
\hline
\end{tabular}

Table 3 berada pada tahap pengujian form login admin, dimana data yang diinput salah ataupun benar yang berada pada kolom "skenario pengujian" akan menghasilkan komentar yang berada pada kolom "hasil yang diharapkan"

4. Pengujian terhadap Form Materi Admin

Tabel 4. Hasil Pengujian Halaman Materi Admin

\begin{tabular}{|l|l|l|l|l|l|}
\hline No. & $\begin{array}{l}\text { Skenario } \\
\text { Pengujian }\end{array}$ & Test Case & Hasil yang diharapkan & $\begin{array}{l}\text { Hasil } \\
\text { pengujian }\end{array}$ & Kesimpulan \\
\hline 1. & $\begin{array}{l}\text { Admin tidak } \\
\text { mengisikan data }\end{array}$ & $\begin{array}{l}\text { Judul materi : } \\
\text { (kosong) deskripsi } \\
: \text { (kosong) }\end{array}$ & $\begin{array}{l}\text { Sistem menolak, “Judul materi } \\
\text { dan dekripsi tidak boleh } \\
\text { kosong” }\end{array}$ & Sesuai harapan & Valid \\
\hline 2. & $\begin{array}{l}\text { Admin mengisi } \\
\text { judul materi, dan } \\
\text { mengosongkan } \\
\text { deskripsi }\end{array}$ & $\begin{array}{l}\text { Judul materi : } \\
\text { TENSES deskripsi } \\
: \text { (kosong) }\end{array}$ & $\begin{array}{l}\text { Sistem menolak, "Dekripsi } \\
\text { tidak boleh kosong" }\end{array}$ & Sesuai harapan & Valid \\
\hline 3. & $\begin{array}{l}\text { Admin mengisi } \\
\text { judul materi dan } \\
\text { deskripsinya }\end{array}$ & $\begin{array}{l}\text { Judul materi : } \\
\text { TENSES deskripsi } \\
: \text { Mempelajari } \\
\text { tense dalam } \\
\text { bahasa inggris } \\
\text { mutlak diperlukan. }\end{array}$ & $\begin{array}{l}\text { Sistem menerima, akses data } \\
\text { tersimpan. }\end{array}$ & Sesuai harapan & Valid \\
\hline
\end{tabular}

Table 4 berada pada tahap pengujian form materi admin, dimana data yang diinput salah ataupun benar yang berada pada kolom "skenario pengujian" akan menghasilkan komentar yang berada pada kolom "hasil yang diharapkan". 


\section{KESIMPULAN}

Berdasarkan hasil penelitian, penulis mendapatkan kesimpulan sebagai berikut :

1. Website belajar grammar ini dapat membantu serta memudahkan user dalam pembelajaran grammar.

2. Sistem informasi e-learning grammar yang dibuat dapat menampilkan materi pelajaran dan memberikan latihan soal serta dapat melihat hasil belajar dari user dengan menampilkan nilai dari latihan soal yang sudah dikerjakan.

3. E-learning sebagai pendukung sistem pembelajaran konvensional yang selama ini digunakan telah berhasil dibangun berdasarkan konten dan struktur yang sesuai dengan kebutuhan pada era teknologi saat ini, yang bisa digunakan untuk belajar, kapanpun dan dimanapun.

\section{SARAN}

Dari kesimpulan yang penulis buat diatas, maka penulis memberikan beberapa saran yang mungkin dapat membantu agar perancangan website ini dapat bekerja secara optimal. Dan untuk menunjang keberhasilan website ini, penulis menyarankan beberapa hal. Antara lain :

1. Melakukan pembaharuan data secara rutin agar informasi yang disampaikan dapat disesuaikan dengan perkembangan informasi yang ada.

2. Mempunyai back-up file dimana untuk mencegah apabila terjadi kesalahan atau permasalahan didalam rancangan website.

3. Melakukan pemeliharaan dan perawatan yang rutin agar kinerja website selalu maksimal serta mengikuti arus perkembangan zaman.

4. Sistem keamanan harus lebih ditingkatkan agar terhindar dari orang-orang yang tidak bertanggung jawab.

\section{DAFTAR PUSTAKA}

[1] Sibero, Alexander F.K. 2013. Web Programming Power Pack. Mediakom, Yogyakarta.

[2] Madcoms. 2011. Aplikasi Web Database dengan Dreamweaver dan PHP MySQL. Andi Offset. Yogyakarta.

[3] Kustiyahningsih, Yeni dan Devie Rosa Anamisa. 2011. Pemrograman Basis Data Berbasis Web Menggunakan PHP dan MySQL. Graha Ilmu. Yogyakarta.

[4] Prasojo, Lantip Diah dan Riyanto. 2011. Teknologi Informasi Pendidikan.Yogyakarta: Gava Media. Surabaya.

[5] Hariyono Rudy, Andrew Mc. Carthy, 2008, ABC plus English Grammar, Gita Media Press, Surabaya. 